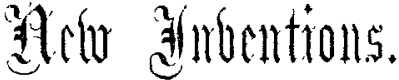

\section{PATTISSON'S CYCLE SADDLE.}

I ENCLOSE an engraving of Captain Pattisson's Cycle Saddle for the relief of perineal pressure, the one which I mentioned I had ridden for a year, and found that it practically does away with perineal pressure. It will be seen that it is open in the middle line in front, and that each side of the saddle is fixed in front to one part of a bifurcated

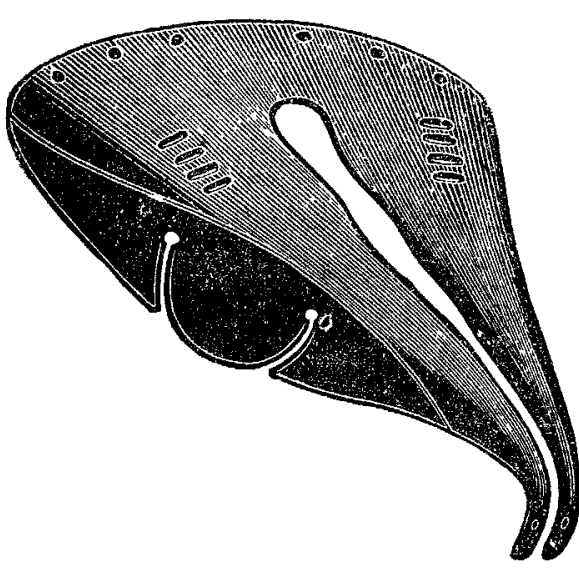
iron support; this bifur cated arrangement pre vents the thighs com pressing the sides to gether, so that actually the middle line of the perineum rests within the open space, and is notexposed to pressure all other saddles I have tried which are open in the middle line are united in front at one point, in consequence the thighs press the sides together, and tend to form a ridge of leather under the middle line of the perineum, and thus press more instead of relieving the pressure. Perineal pressure is a cause of so much suffering and inconvenience to cyclists that $I$ venture to send this engraving and note for publication. The saddle is, I understand, to be exhibited at Messrs. Foley \& Webb's stall at the Cycle Exhibition at the Crystal Palace next week.

E. D. ToMlinson, M.D.

\section{MEDICAL SPIROMETER.}

WE have had an opportunity of testing this instru. ment, and find that it affords an accurate, ready, and simple means of ascertaining the cubical capacity of the lnngs. As will be seen by the illustration, its external construction resembles a dining-room clock. The work-

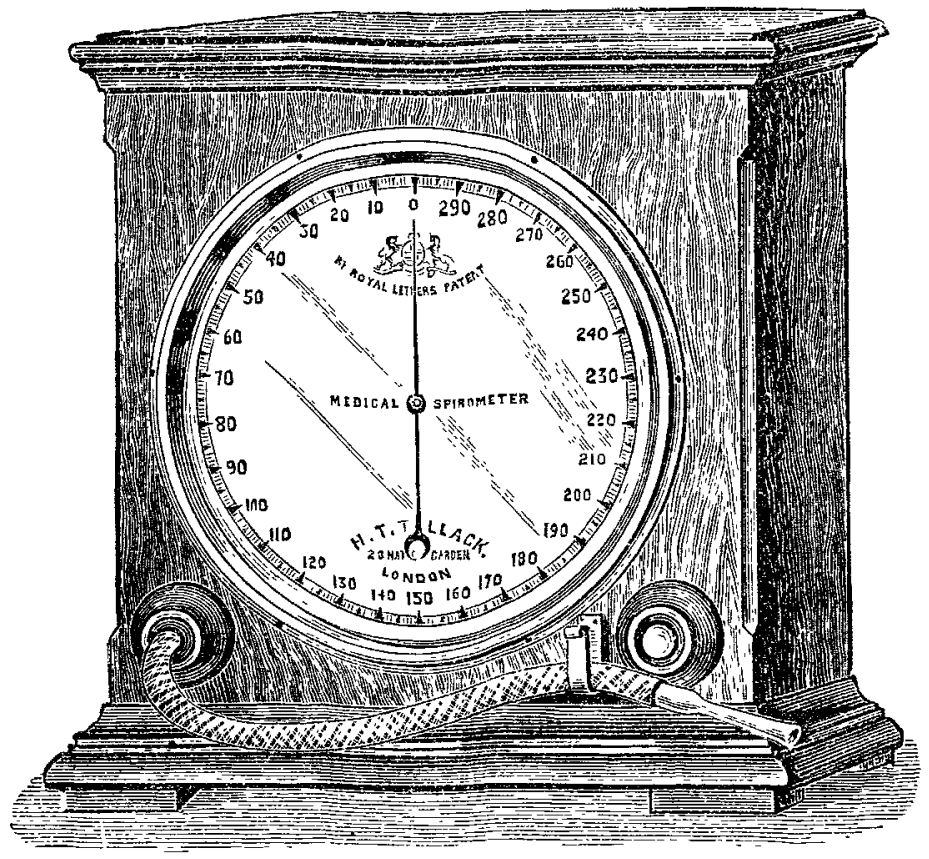

manship it displays is of a high character, which, together with its ornamental appearance, renders it an article of furniture well fitted to adorn a well-appointed consulting room. This spirometer will doubtless prove of service to physicians as a convenient aid to diagnosis in diseases of the chest.

\section{WHOLESALE LEAD POISONING AT SHEFFIELD.}

To the Editors of THE LANCET.

SIRs,-Your observations in THE LANCET of Jan. 18th on the dangerous state of affairs existing at Sheffield, involving the health and lives of such a number of human creatures by that terrible malady, poisoning by lead, induce me to send you an analogous case which I came across in my wanderings some years ago.

In $1840 \mathrm{I}$ was a passenger in the ship China. We put into the Cape of Good Hope to refresh and take in water. After a time at sea a large number of the crew and passengers exhibited the ordinary symptons of lead poisoning, some, as a matter of course, more severe than others. It was apparent, on investigating the matter in company with the ship's surgeon, that the water was contaminated. Contrasted with the vater of the Thames, which we had on starting, and which at first was not fit for ordinary use in its natural state until after it had fermented and settled down sweet, the water which we obtained at the Cape was tempting, and in the warm weather that prevailed more of it was consumed, doubtless, than otherwise would have been. After holding a council of war as to the cause, we arrived at the true sonrce of the evil. It appeared that the water at the Cape which supplied the shipping in those days came down in rivulets from the verdure-clad slopes of the ranges of Table Mountain, which were studded towards the bottom with vineyards; thence it was conveyed in pipes, partly leaden, to the piers, and thence into the ships. It cane out that the vine people were accustomed, as farmers generally are, to throw into the pits and on the banks of the streams adjacent the vine stalks and remains of the vintage, which decomposing, acetous fermentation was set up, and, impregnating the water in its rapid descent, would dissolve quantities of lead, forming the soluble acetate of lead, and also the more deadly carbonate of lead. Such was the history and the solution of the alarming phenomena. As you truly say, the victims of lead poisoning pass a long incubative period whilst the poison is being deposited, and it is not till the system is saturater, or a larger dose than usual is absorbed, that the definite symptoms are produced. That is true of poisoning from carbonate of lead, but in our case the symptoms were immediate and acute, the agent being the more soluble acetate. The generation of the acetic acid would vary with the seasons; when hot and moist and in autumn it would be in greater quantity. Fortunately our supply of Thames water had been large.

On perusing your suggestive remarks, it strack me that it was my duty to give you briefly the above case, which, though occurring fifty years ago, is as vivid in my mind as when it happened. Perhaps the Water Committee of the Town Council of sheffield may trace the contamination of their water-supply to acids from some of their factories, or from "decayed leaves, rushes, and weeds," as you suggest, which in these past few years of excessive, and, indeed, rank and morbid vegetable growths under our highly surcharged electrical atmo. sphere, as in deleterious insect life, may have been developed into increased and even virulent activity when coming in contact with the so soluble metal as lead. Truly on all sides, and in these last days of the world's agony, "there is death in the pot," requiring all our energies and researches to discover the handful of " nieal" appointed of God to alleviate, if not to stave off, the lurking microbe. I am, Sirs, yours truly,

T. W. CHRISTIE, M.R.C.S. Eng.

Ash House, Broad-green, Liverpool, Jan. 21st 1890

Football Casualties.-At a football match at Penarth on Saturday, between Penarth and Newport, a man named England sustained a fracture of the thigh. During a match on the same day, between Armley and Outwood, several accidents occurred to the Armley team. $J$. Oddley fell and dislocated his arm in two places, Whittaker severely sprained his ankle, while two other members were more or less injured about the head and face. Two men (one from each team) were exre'led for rough play. 